\title{
A PROPOSED REFORM IN TECHNICAL TRAINING
}

BY EDWARD B. RAYMOND.

Those who are called upon to select a man for certain duties, although able to form in their own minds an opinion as to the qualifications necessary, frequently experience difficulty in finding such a person as they require. Most men do not appear to realize that intelligent and conscientious work is the basis of advancement, and that industry guided by intellect is invincible. Although this statement may not be generally appreciated, it is the result of many years of experience in the selection of employes, and applies to college graduates as well as others. This condition of affairs is largely due to early training. Young men who have been reared without due consideration of the economy and self-denial which has enabled their parents to support them while they were being educated, do not take their life work with the necessary earnestness, and are apt to drift along without thought as to whether or not their efforts are tending in the proper direction.

As under existing social conditions there can be no scientific selection of parents, we are necessarily compelled to deal with the problem as it confronts us, so that it is by no means a simple matter to determine the most suitable future employment for a boy who has not yet developed any leaning toward a distinctive line of work.

When a boy enters the High School, either parents or teacher should decide upon the line of his life work. It is too early for him to judge of his own natural ability, and it is the experience of the writer that most college graduates fail in determining 
their proper sphere of action, and this is usually apparent to themselves. It is so seldom that positive tendencies appear in a boy, that his natural ability should be carefully studied, and a decision reached as to his future course.

Some of the great masters of the violin will not undertake to teach a pupil who has passed his eighth year, as they hold that the initial training should begin at that age. The writer believes that a similar rule should apply to engineers, and that this work should be started in the High School.

Supposing that electrical engineering has been chosen. What qualifications are essential to success? The student should possess health, character, courage and intellect. He should be thoroughly impressed with the understanding that work, hard work, constant work, is the absolutely essential foundation for future success.

These conditions refer more especially to young men of average ability. The exceptions, who are generally recognized as men of genius, are exotics, and the ordinary rules of advancement do not apply to them. They soar above their colleagues by reason of their superior fitness, and we admire and honor them for their recognized ability, without attempting to analyze the causcs, for we know that to be impossible.

Every man has the ability to do certain things with the best possible results. One of these things is work. But in addition to this we should have trained minds, and accumulate knowledge of detail.

There exists in the electrical profession above all others. a demand for the lowest grade of work as well as the highest. The engineer should be thoroughlv trained in the various lines of practical work, in order to instruct or guide others. He must possess the necessary data, and his mind must be trained to utilize it, in order to make the proper calculations, and predetermine results. While all this is true in any branch of engineering, it is especially so in the electrical, as we cannot rely simply upon judgment and intuition. Something more is required to enable an engineer to design and calculate properly the required output of an induction motor, or determine the phases of cross-currents between alternators, whose prime movers are pulsating in frequency, or hundreds of other cases arising in practice.

To sum up, therefore, we need broad-minded men with intellect, strength, training and purpose. How can we best obtain them? We naturally turn to the college-but how much is asked of it? 
Men have entered without knowledge of the line of work they are to adopt; often deficiently trained. Their view of life is a fraction with ease and comfort cubed as the numerator, with work to the one-third power in the denominator. To make successful men, this fraction must be reversed. If not done in college, it will be done through stress of the duties which the graduate assumes upon beginning his life work. If this training comes too late, another man already seasoned will forge ahead, for the handicap is too serious for a term of active life, none too long at the best.

Our professors, then, should be men of force of character as well as of intellectual attainment, and the courses at college should be so arranged that recitation rooms and laboratories may be regarded by the students as we look upon our offices.

At this stage of the young man's education, it is the writer's idea that details should be put into second place, as at that time of life they are likely to be only superficial.

The technical college should attract by its atmosphere only men with a purpose, and so the training must be correctly prepared. Some of our colleges make a poor showing in this respect, possibly from improper organization, failure to reach the individual, or inability to inspire the working spirit. It is the writer's opinion that the colleges should return to the district school principle by stopping elective courses, contracting the list of studies and by encouraging the students to specialize. Then, if the professor is able to get hold of each student personally and instill into his mind the necessity for hard work, a long step will have been taken toward the perfect engineering course. The young man graduated from such an institution will go out into the world with a real equipment for successful work in his particular sphere of usefulness.

One of the most essential qualifications of the successful engineer is that he shall be filled with a desire for continualstudy. Then is the time for him to get his knowledge of real detail, amplifying the general knowledge obtained in college by practical investigation. In short, the college graduate should consider that the knowledge gained at the university is only a start and not a suggestion of a finish.

The writer is a strong advocate of the strictly technical course in the training of electrical engineers. The technical college should drop from its curriculum studies which are likely to be taken up after graduation. The writer believes that such a 
college will turn out men better qualified for professional work, for when properly trained the graduated engineer will devote a portion of each week to study, and will do this from a natural inclination to study. Details of all subjects that he lacks will be obtained without great effort. As he accumulates money, he will naturally turn to political economy and business law; reading will turn him to history, and daily writing will lead him to use good grammar and expression.

The chances of success in the case of a man thoroughly grounded in technical information are vastly better than those of the man who has gained general information at the expense of technical training. This point is well illustrated by the wonderful success of many of the most noted men in our profession without college training. They had the essential characteristics for success, mind, application and a desire to study, and their success has been the result of those qualifications.

The ideal college, then, would be that which teaches simplicity, concentration, hard work; which discourages all that is supe: ficial; which weeds out the studies that are not essential to the particular course being pursued, and devotes all the more attention to those that are essential.

For the boy in the High School who intends to be an electrical engineer, it may be suggested that for about six weeks of his last two summer vacations at the High School, he should work in the machine shop of some manufacturing electrical concern. This will give him very valuable initial experience. During his college course the student in electrical engineering should spend a part of each summer in similar practical work, supplementing it, perhaps, with work in a foundry or pattern shop. The draughting-room at college would mean much more to such a man than to the ordinary student.

The writer would suggest, therefore, in line with these ideas, that from college electrical courses such studies as French and German, rhetoric and English composition, history, English literature and political economy, be dropped. One college, to the writer's knowledge, has, besides all these studies, dropped bridge construction, surveying and highway building. In place of the studies discarded, more stress could be laid upon mathematics, physics, mechanics, chemistry, thermodynamics and the laws of electricity. There should be enough of these studies to give, in addition to mind training, excellent detail knowledge of the subjects studied. 
A feature of the college that may be made especially interesting and instructive is the arrangement of frequent lectures, or talks, by men eminent in their profession. Such men are always willing to give to others the benefit of their own great experience; and their talks must be inspiring to the student, even if the lecture is not understood in detail. Such talks are instructive for the professor as well as the undergraduate, giving excellent inspiration by illustrating what has actually been accomplished.

In conclusion let me say that I do not wish to give the impression that the college is a failure. It is doing wonderful work, and deserves great credit; but in electrical engineering education as well as in everything else, there is nothing that cannot be improved. 